\title{
CARACTERIZAÇÃO FÍSICO-QUÍMICA DE POLPA DE ACEROLA IN NATURA E LIOFILIZADA PARA PREPARAÇÃO DE SORVETES
}

\author{
C. C. de S. BERY ${ }^{1 *}$, A. C. A. VIEIRA ${ }^{2}$, N. C. GUALBERTO ${ }^{1}$, A. A. de CASTRO ${ }^{3}$, G. F. da \\ SILVA $^{4}$, E. D. A. SANTOS ${ }^{5}$ e B. S. dos SANTOS $^{6}$ \\ ${ }^{1}$ Universidade Federal de Sergipe - UFS, Laboratório de Tecnologias Alternativas \\ ${ }^{2}$ Universidade Federal de Sergipe - UFS, Mestre em Ciência e Tecnologia em Alimentos \\ ${ }^{3}$ Universidade Federal de Sergipe - UFS, Departamento de Tecnologia de Alimentos \\ ${ }^{4}$ Universidade Federal de Sergipe - UFS, Departamento de Engenharia de Petróleo \\ ${ }^{5}$ Universidade Federal de Sergipe - UFS, Graduanda em Engenharia de Alimentos \\ ${ }^{6}$ Universidade Federal de Sergipe - UFS, Graduada em Engenharia de Alimentos \\ *E-mail para contato: crisbery@ig.com.br
}

\begin{abstract}
RESUMO - A composição nutricional da acerola, com elevado conteúdo de vitamina $C$, presente na sua polpa, a sobrepõe sobre as demais frutas pela possibilidade de processamento/industrialização e armazenamento com a manutenção de valores nutricionais ainda elevados. O objetivo do trabalho é caracterizar fisico-quimicamente polpa de acerola in natura e liofilizada para preparação de sorvetes de acerola. As análises físico-químicas realizadas foram: acidez, cinzas, sólidos solúveis, proteínas, $\mathrm{pH}$ e vitamina $\mathrm{C}$. Como resultado teor de sólidos solúveis e $\mathrm{pH}$ não diferiram significativamente entre as amostras, obtendo valores medianos de 7,5 e 3,1, respectivamente. Quanto às outras caracterizações a polpa de acerola liofilizada diferiu significativamente quando comparado com a polpa in natura. Esse resultado esta de acordo com a literatura estudada, pois ao liofilizar um produto, devido à perda de água, este, concentra suas propriedades funcionais proporcionando ao produto melhor qualidade nutricional.
\end{abstract}

\section{INTRODUÇÃO}

A acerola (Malphigia emarginata D. C.) é uma planta frutífera originada das Antilhas, norte da América do Sul e América Central (BRUNINI et al., 2007). Também conhecida como "cereja tropical", permaneceu florescendo e frutificando em terras americanas sem provocar maiores atenções, no entanto só a partir dos anos 40 foram despertados o interesse e os estudos sobre suas potencialidades econômicas, quando cientistas porto-riquenhos encontraram na porção comestível da fruta altos teores de vitamina $\mathrm{C}$ e, por ser uma planta rústica e resistente, propagou-se naturalmente e com facilidade por todo mundo (BEHLING $e t$ $a l .$, 2007). 
A acerola (Malpighia emarginata D.C.) contém alto teor de ácido ascórbico, que como os carotenóides e as antocianinas também presentes nessa fruta são compostos bioativos que se destacam como antioxidantes, elevando esse fruto ao campo dos alimentos funcionais (FREITAS et al., 2006). A polpa de fruta representa alternativa de consumo para os mercados nacionais ou internacionais, mesmo em períodos de entressafra de produção (LOPES, 2005). No entanto, o processamento afeta o conteúdo, a atividade e a biodisponibilidade dos componentes bioativos desses frutos (MAIA et al., 2007).

Atualmente tem-se empregado novas tecnologias que permitem processar a fruta na forma de pó, fazendo com que o fruto, que antes era consumido só em sua época de safra, hoje possa ser consumido em qualquer período do ano. O processo mais utilizado é a liofilização que faz com que a água contida no produto, passe do estado sólido (produto congelado) para o estado gasoso sem passar pelo estado líquido, ocorrendo desta forma, o processo de sublimação (IBARZ e BARBOSA - CÁNOVAS, 1999).

Nas últimas décadas, muitos estudos foram realizados em relação à desidratação de polpa de frutas, voltados principalmente no sentido de aumentar a retenção das propriedades nutritivas e sensoriais do produto desidratado mediante as alterações dos processos já existentes ou aplicação de novas técnicas. Dentre elas destacam-se a desidratação em leito de espuma e a liofilização (SOUZA, 2011).

O objetivo deste trabalho é caracterizar físico-quimicamente a polpa de acerola in natura e liofilizada para preparação de sorvetes de acerola.

\section{MATERIAL E MÉTODOS}

O fruto da acerola foi obtido no Centro de Abastecimento de Aracaju (CEASA) e levado ao Laboratório de Produtos de Origem Vegetal (LPOV) do Departamento de Tecnologias de Alimentos - DTA pertencente à Universidade Federal de Sergipe - UFS.

A fruta passou pelo processo de higienização e sanitização e em seguida foi realizado o processo de despolpamento da mesma. A polpa de acerola foi pesada (espessura e peso iguais), acondicionadas em potes de poliestireno $(100 \mathrm{~mL})$ e armazenados em freezer $\left(-18^{\circ} \mathrm{C}\right)$ para congelamento. Por conseguinte a polpa foi liofilizada obtendo-se amostras secas de polpa de acerola. A Figura 1 mostra o fluxograma do processo acima descrito. 


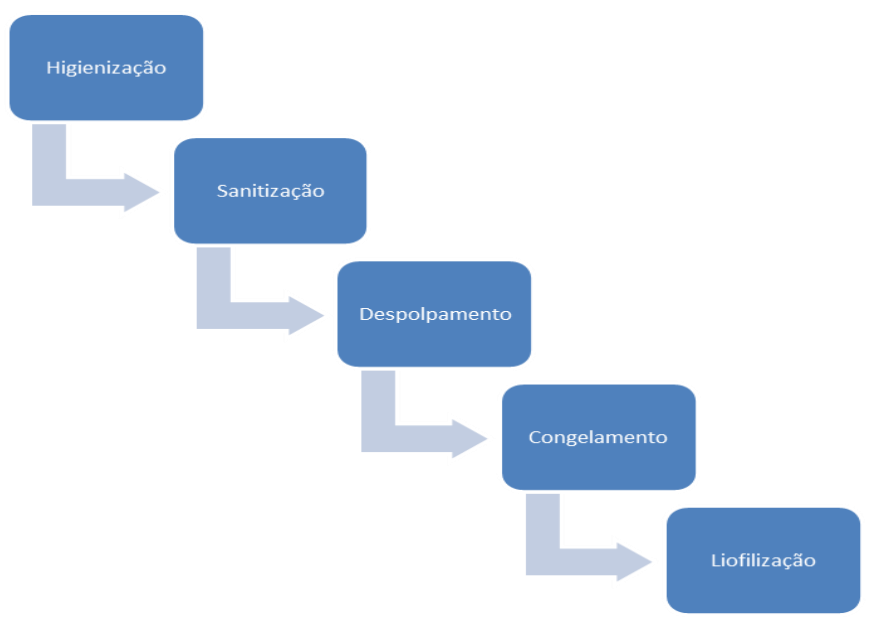

Figura 1 - Fluxograma de processos para obtenção de polpas in natura e liofilizada.

As análises físicas químicas realizadas na polpa in natura e liofilizadas foram: acidez, cinzas, sólidos solúveis, proteínas, $\mathrm{pH}$ e vitamina $\mathrm{C}$, segundo a metodologia descrita por Adolfo Lutz (2004).

As análises estatísticas foram realizadas utilizando-se o Programa Assistat R versão 7.7 beta (Software livre), e foram expressos em tabelas de análise de variância (ANOVA) $(\mathrm{p} \leq 0,05)$ pelo teste de médias de Tukey.

\section{RESULTADOS E DISCUSSÕES}

Na Tabela 1 estão apresentados os valores médios da caracterização físico-química das polpas de acerolas in natura e da polpa liofilizada. 
Tabela 1 - Valores médios da caracterização físico-química das polpas de acerola in natura e liofilizada

\begin{tabular}{lcc}
\hline \multicolumn{1}{c}{ Parâmetro } & Polpa de Acerola in natura & Polpa de acerola liofilizada* \\
\hline pH & $3,24^{\mathrm{a}}$ & $3,14^{\mathrm{a}}$ \\
Acidez (\% ac. Cítrico) & $1,44^{\mathrm{b}}$ & $3,03^{\mathrm{a}}$ \\
Sólidos solúveis ( ${ }^{\circ}$ Brix) & $7,6^{\mathrm{a}}$ & $7,5^{\mathrm{a}}$ \\
Cinzas (\%) & $0,23^{\mathrm{b}}$ & $3,44^{\mathrm{a}}$ \\
Proteínas (\%) & $0,67^{\mathrm{b}}$ & $6,90^{\mathrm{a}}$ \\
\hline Vitamina C (mg AA/100g) & $416,14^{\mathrm{b}}$ & $1571,05^{\mathrm{a}}$ \\
\hline
\end{tabular}

*Média \pm desvio-padrão $(\mathrm{n}=3)$. Letras minúsculas distintas na mesma linha representam diferenças significativas entre as médias pelo teste de Tukey $(p<0,05)$ para amostras distintas na mesma análise.

Os valores médios do $\mathrm{pH}$ da polpa de acerola in natura e da polpa liofilizada não diferiram estatisticamente entre si a $5 \%$ de probabilidade pelo teste de Tukey. $\mathrm{O} \mathrm{pH}$ da polpa de acerola in natura foi de 3,24 e da polpa liofilizada 3,14 caracterizando ambos como um produto ácido. Resultados de valores de $\mathrm{pH}$ semelhantes foram encontrados por Menezes et al. (2009) ao realizar a secagem da polpa e frutos de acerola verde em estufa por circulação de ar a $70^{\circ} \mathrm{C}$ e por processo de liofilização para obtenção de um pó para ser utilizado como suplemento alimentar, encontrando valores de $\mathrm{pH}$ de 3,45 e 3,43 respectivamente.

Outro parâmetro que não diferiu estatisticamente foram os sólidos solúveis. Para a polpa de acerola in natura e a polpa liofilizada foram encontrados valores de 7,6 e 7,5 respectivamente. Esta análise, segundo Adolfo Lutz (2004), é utilizada para determinar a concentração de sólidos solúveis em soluções aquosas de açúcar.

A porcentagem de ácido cítrico para a polpa de acerola in natura e para a polpa de acerola liofilizada foi de 1,44 e 3,03\% diferindo estatisticamente. O processo de liofilização tem como característica concentrar os compostos nutricionais existente na amostra in natura tornando este produto rico quanto a suas propriedades funcionais. A mesma explicação é para os outros parâmetros avaliados neste trabalho: \% cinzas, \% proteínas e vitamina C. Nestes, segundo a Tabela 1, nota-se que os valores encontrados para a polpa de acerola liofilizada são significativamente maiores quando comparados com a polpa de acerola in natura. Dentre estes parâmetros o mais significativo é a vitamina $C$, já que a fruta, acerola, é rica deste composto importantíssimo para estimular a defesa e regular o metabolismo do organismo. 
Para a preparação de sorvetes é necessário que este obtenha valores nutricionais semelhantes ou maiores que a matéria-prima utilizada, o que torna a polpa de acerola liofilizada excelente alternativa para a preparação de sólidos gelados comestíveis.

\section{CONCLUSÃO}

A polpa de acerola liofilizada apresentou maiores conteúdos de vitamina $\mathrm{C}$, proteínas, cinzas e acidez, visto que esse é um processo de secagem que permite remoção do conteúdo de água livre do produto sem interferir nas demais qualidades nutricionais do produto.

Diante dos resultados obtidos pode-se concluir que a polpa de acerola in natura e a polpa de acerola liofilizada podem ser aplicados para a preparação de sorvete de acerola preservando significativa quantidade do seu conteúdo de vitamina C.

\section{REFERÊNCIAS BIBLIOGRÁFICAS}

BEHLING, A.; MAFRA, C.; COLOMBO, R.; BAMBERG, R. Cultura da Acerola. Frederico Westphalen: Universidade Federal de Santa Maria, 2007.

BRUNINI, M. A.; MACEDO, N. B.; COELHO, C. V.; SIQUEIRA, G. F. Caracterização física e química de acerolas provenientes de diferentes regiões de cultivo. Revista Brasileira de Fruticultura, v. 26, n. 3, p. 486 - 489, 2004.

FREITAS, C. A. S.; MAIA, G. A.; COSTA, J. M. C.; FIGUEIREDO, R. W.; SOUZA, P. H. M. Acerola: produção, composição, aspectos nutricionais e produtos. Revista Brasileira de Agrociência, v. 12, n. 4, p. 395 - 400, out.dez., 2006.

IBARZ, A. e BARBOSA-CÁNOVAS, G. V. Operaciones unitárias de la ingenieria de alimentos. Lancaster: Technomic Publishing. 1999.

INSTITUTO ADOLFO LUTZ. Normas analíticas do Instituto Adolfo Lutz. 3. ed., São Paulo: IAL, Brasil, 2004.

LOPES, A.S. Pitanga e acerola: estudo de processamento, estabilidade e formulação de néctar misto. 2005. 193 p. Tese (Doutorado em Tecnologia de Alimentos) - Faculdade de Engenharia de Alimentos, Universidade Estadual de Campinas, Campinas, 2005.

MAIA, G. A.; SOUSA, P. H. M. de; SANTOS, G. M. dos; SILVA, D. S. da; FERNANDES, A. G.; PRADO, G. M. Efeito do processamento sobre componentes do suco de acerola. Ciência e Tecnologia de Alimentos, v. 27, n.1, p.130-134, 2007.

MENEZES, A. R. V.; JÚNIOR, A. S.; CRUZ, H. L. L.; ARAUJO, D. R.; SAMPAIO, D. D. Campina Grande: Revista Brasileira de Produtos Agroindustriais, v.11, n.1, p.1 - 8, 2009.

SOUZA, V. C. Efeito da liofilização e desidratação em leito de espuma sobre a qualidade do pó de polpa de cupuaçu (Theobroma grandiflorum). Itapetinga - BA: UESB, 2011. (Dissertação - Mestrado em Engenharia de Alimentos). 